\title{
The CMC-like behaviour of bile salts as probed by photoexcited Rose Bengal
}

Alain Seret and Mohamed-Ali Bahri

Université de Liège (ULg), Department of Physics (DEPHY), Institut de Physique, B5, B-4000 Liège1, Belgium

E-mail of Alain Seret: aseret@ulg.ac.be

Email of Mohamed-Ali Bahri: M.Bahri@ulg.ac.be

Corresponding author: Alain Seret, Université de Liège (ULg), Department of Physics, Institut de Physique, B5, B-4000 Liège1, Belgium

Phone +32-4-3663705, Fax +32-4-3663629, e-mail aseret@ulg.ac.be 


\section{Abstract}

The onset of the aggregation process in aqueous bile salt (BS) solutions remains a debated question. This study aimed at investigating this point through the detection of BS monomers and small aggregates using the dye Rose Bengal. Results showed that a few small BS aggregates led to a red shift of the absorption spectrum, while the BS monomer reacted with the photo-induced semi-oxidized dye and decreased its decay rate constant. The dye was dissolved in aqueous solution $\left(10 \mathrm{mmol} \mathrm{dm}^{-3} \mathrm{NaOH}\right)$ of sodium cholate $(\mathrm{NaC})$, deoxycholate $(\mathrm{NaDC})$, chenodoxycholate $(\mathrm{NaCDC})$, dehydrocholate $(\mathrm{NaDHC})$, glycocholate $(\mathrm{NaGC})$ glycodeoxycholate (NaGDC), taurocholate (NaTC), taurodeoxycholate (NaTDC) and the zwitterionic analogue of sodium cholate called CHAPS. BS aggregates were detected at concentrations well below the concentration above which any added bile salt molecules participate in the aggregation process for all trihydroxy bile salts and for CHAPS but not for the dihydroxy bile salts. No aggregation of $\mathrm{NaDHC}$ could be observed in the studied concentration range $\left(\leq 10 \mathrm{mmol} \mathrm{dm}^{-3}\right)$. The presence of 150 and $600 \mathrm{mmol} \mathrm{dm}{ }^{-3}$ sodium ions lowered the concentration below which BS are mainly monomers for dihydroxy but not for trihydroxy bile salts. As already proposed by others, the use of the concept of Micellar Dissociation Concentration (MDC) is suggested here instead of the classical Critical Micelle Concentration (CMC).

Keywords: bile salt; aggregation; critical micelle concentration; monomer; Rose Bengal 


\section{Introduction}

For many years, the measurement and the existence itself of the critical micelle concentration $(\mathrm{CMC})$ in aqueous solutions of bile salts (BS) has been a debated question [1-6]. It has been shown that the $\mathrm{CMC}$ values determined by the same technique in different laboratories are very dispersed, especially for the trihydroxy bile salts [2,6-9]. Furthermore, it has been demonstrated that the CMC measurements made in one laboratory using different techniques are also not in good agreement $[2,10-12]$. Although it is recognized that the CMC values obtained using different properties are not quite identical [13], such large discrepancies between published CMC values are generally not observed in the case of synthetic aliphatic detergents. It has also been claimed that two types of CMC exist $[3,5,6]$. Therefore, some authors have concluded that the notion of CMC does not apply to aqueous solutions of bile salts $[1,3,14,15]$. Although these problems have long been recognized, new tentative methods for $\mathrm{CMC}$ determination of bile salts appear regularly.

In order to clarify the CMC problem of bile salts, a first step would be to check whether all the requirements of the definition of $\mathrm{CMC}$ could be met by an aqueous solution of bile salts. The International Union for Pure and Applied Chemistry (IUPAC) defines the CMC as follows [13]: "There is a relatively small range of concentrations separating the limit below which virtually no micelles are detected and the limit above which virtually all additional surfactant form micelles. Many properties of surfactant solutions, if plotted against the concentration, appear to change at a different rate above and below this range. By extrapolating the loci of such a property above and below this range until they intersect, a value may be obtained known as the CMC". This definition of the CMC comprises at least three very important statements. First, above the CMC, all aggregates should be identical. This statement is really essential. Indeed, most of the techniques that are used to measure the CMC detect the aggregates, and the aggregates of different size or shape are weighted differently according to the technique $[9,16,17]$. This weighting difference leads to CMC values that vary according to the technique used to determine them. Second, the range of 
concentrations below which virtually no micelles exist and above which all additional surfactant forms micelles should be small. As their aggregation process seems to be stepwise with the formation of micelles of different shape and size $[3,5,6,9]$, the bile salts do not fulfil these first two statements. Third, below the CMC, any aggregate should not exist ("virtually no micelles are detected").

A photophysical study in aqueous solutions of sodium taurocholate [18] has shown that Rose Bengal (RB) dye allows the investigation of the last two statements. First, RB semi-oxidized radical, which can be easily produced and observed in air-saturated solutions by means of microsecond flash photolysis, reacts with the BS monomer. Consequently, the decay rate constant of the radical increases linearly with the total BS concentration until aggregates appear. Second, the dye ground state absorption spectrum is very sensitive to the presence of aggregate. Like the larger aggregates formed at higher concentration, the first small aggregates built at low BS concentration possess solubilization sites to which the dye molecule in its ground electronic state can bind. Bound RB molecules are characterized by a red shifted absorption spectrum. RB presents therefore the least common property by which to probe both the bile salt monomers and aggregates. To the best of our knowledge, no other spectroscopic probe previously used to investigate the bile salt aggregation process has presented this particularity.

In the present study, RB was used to determine the concentration range over which any rise in BS concentration results in a corresponding increase in BS monomer concentration and the lowest BS concentration for which aggregates are detected. Sodium cholate $(\mathrm{NaC})$ and deoxycholate $(\mathrm{NaDC})$, their glycine (NaGC and $\mathrm{NaGDC}$ ) and taurine (NaTC and $\mathrm{NaTDC}$ ) conjugates, sodium chenodoxycholate (NaCDC) and dehydrocholate $(\mathrm{NaDHC})$ and a zwitterionic analogue of sodium cholate [19], the so-called CHAPS, were studied in $10 \mathrm{mmol} \mathrm{dm}^{-3} \mathrm{NaOH}$ aqueous solutions. The basic $\mathrm{pH}$ is required to avoid protonation of the dye [18]. Solutions containing 150 and $600 \mathrm{mmol} \mathrm{dm}^{-3}$ sodium ions, obtained by addition of $\mathrm{NaCl}$, were also investigated. 


\section{Materials and methods}

\subsection{Products}

Bile salts were obtained from Calbiochem (La Jolla, CA), except for NaDHC, which was supplied by Fluka (Buchs, Switzerland). Sodium hydroxide and sodium chloride were pro analysis products from Merck (Darmstadt, Germany). Rose Bengal was obtained from Eastman Kodak (Rochester NY) and was carefully purified [20]. $\mathrm{K}_{4} \mathrm{Fe}(\mathrm{CN})_{6}$ was an analytical grade product from Merck (Darmstadt, Germany). Laboratory distilled and deionized water was used for all experiments. BS stock solutions were prepared daily by dissolution of the solid in this water.

\subsection{Spectroscopic experiments}

Absorption and flash photolysis measurements were carried out using the instruments and techniques previously described $[18,21,22]$. The dye concentration was $4.5 \times 10^{-3} \mathrm{mmol}$ $\mathrm{dm}^{-3}$ in all experiments. The transient absorbance decay curve of the RB semi-oxidized radical was fitted by first-order kinetics and the semi-oxidized RB decay rate constant $(k)$ was obtained. The reaction rate constant between semi-oxidized RB and a compound (either bile salt or $\left.\mathrm{K}_{4} \mathrm{Fe}(\mathrm{CN})_{6}\right)$ was obtained by linear regression from the plots of $\Delta k=k-k_{0}$ ( $k_{0}$ being the rate constant in absence of the compound) versus the compound concentration. The error on the wavelength of absorption maximum and the semi-oxidized RB decay rate constant was calculated from two sets (one in pure aqueous solution and one in $5 \mathrm{mmol} \mathrm{dm}^{-3}$ NaTC aqueous solution) of ten replicate measurements. Both two standard deviations and the maximum difference to the mean were lower than or equal to $0.5 \mathrm{~nm}$ for the wavelength of absorption maximum and to $5 \%$ for the semi-oxidized RB decay rate. Therefore $0.5 \mathrm{~nm}$ was considered as the error on the wavelength of absorption maximum and $5 \%$ as the relative error on the semi-oxidized RB decay rate. Consequently, a red shift of the absorption maximum was considered to be significant when it reached $1 \mathrm{~nm}$ and the relative error was evaluated to be lower than $10 \%$ for $\Delta k$ and $20 \%$ for the reaction rate constants. 


\section{Results}

The most striking results of the present study are summarized in Tables 1, 2 and 3 for aqueous solutions of various bile salts containing 0,150 and $600 \mathrm{mmol} \mathrm{dm}^{-3} \mathrm{NaCl}$, respectively. PS stands for the bile salt concentration above which a red shift of at least $1 \mathrm{~nm}$ was recorded for the RB absorption maximum.

Examples of plots of $\Delta k$ versus bile salt concentration are given in Fig. 1. At low bile salt concentration, $\Delta k$ was generally a linear function of the bile salt concentration.

Thereafter, a break point (BP) generally occurred, above which $\Delta k$ was roughly bile salt concentration independent (Fig. $1 \mathrm{~b}-\mathrm{d}$ ). Above this break point, $\Delta k$ could only be measured over a small concentration range, because the initial yield in semi-oxidized radical decreased dramatically. With CHAPS, this decrease occurred at low concentration. The decay rate constant of semi-oxidized RB could only be measured below $3 \mathrm{mmol} \mathrm{dm}^{-3}$ and it increased linearly with the CHAPS concentration. Therefore, it could be inferred that BP exceeded 3 $\mathrm{mmol} \mathrm{dm}^{-3}$ for CHAPS. In the case of $\mathrm{NaDHC}, \Delta k$ increased linearly with $\mathrm{NaDHC}$ concentration up to $10,6,5 \mathrm{mmol} \mathrm{dm}^{-3}$ in 0,150 and $600 \mathrm{mmol} \mathrm{dm} \mathrm{Na}^{-3}$ aqueous solutions, respectively (Fig. 1a). Above these concentrations, the decay of RB semi-oxidized radical became too fast to be accurately detected by our microsecond flash photolysis equipment. Consequently, it could be inferred that BP was higher than $10,6,5 \mathrm{mmol} \mathrm{dm}^{-3}$ for $\mathrm{NaDHC}$ in aqueous solutions containing 0,150 and $600 \mathrm{mmol} \mathrm{dm}^{-3} \mathrm{Na}^{+}$, respectively. With $\mathrm{NaCDC}$ and $\mathrm{NaGDC}$, any increase in $\Delta k$ could be observed in some $\mathrm{NaCl}$ containing solutions (Tables 2 and 3). BP was therefore not measurable. The measured reaction rate constants $\left(k_{X B}\right)$ between RB semi-oxidized radical and BS monomer are reported in the last column of Tables 1,2 and 3.

Finally, the reaction rate constant $\left(k_{x 4}\right)$ between RB semi-oxidized radical and $\mathrm{Fe}(\mathrm{CN})_{6}{ }^{4-}$ was determined below and above BP. The obtained values are reported in the 
fourth and fifth columns of Tables 1, 2 and 3 . When BP was not observable, the $k_{x 4}$ value was determined at several arbitrary chosen bile salt concentrations. The obtained values were always in excellent agreement $(\leq 10 \%)$ and were therefore averaged. The mean values are given in the fourth column of Tables 1, 2 and 3.

\section{Discussion}

The break point (BP) in the plots of $\Delta k$ against bile salt concentration (Fig. 1) had been previously assimilated to the concentration above which the aggregation of bile salt becomes extensive: the bile salt anions are embedded in aggregates and are therefore no longer accessible to the semi-oxidized RB radical [18]. This reasoning only holds if the semioxidized radicals, which are detected, are moving freely in the aqueous phase. This statement was examined by determining the reaction rate constant $\left(k_{x 4}\right)$ between RB radical and $\mathrm{Fe}(\mathrm{CN})_{6}{ }^{4-}$, whose electrical charges and hydrophilic nature are assumed to restrict mobility to the aqueous phase [22]. $k_{X 4}$ values were determined below and above BP (Tables 1, 2 and 3). They did not significantly differ from the values determined in the absence of bile salt, which is reported in the first line of the tables. Consequently, the statement of detecting only semi-oxidized RB radicals free in the aqueous phase is fulfilled and BP can be interpreted as the upper limit of the concentration range over which any increase in bile salt concentration leads to a corresponding increase in bile salt monomer concentration.

The initial yield in semi-oxidized RB decreased progressively when the bile salt concentration exceeded a certain value. With CHAPS, this phenomenon precluded the observation of BP. Semi-oxidized RB is produced in the quenching reaction of RB triplet state by dioxygen $[22,23]$. In NaTC solutions, it was observed that RB triplet state could reside in bile salt aggregates [18]. The decrease in radical initial yield could be a consequence of this change in the solubilization site of the dye triplet state.

Due to the $10 \%$ experimental uncertainty over the decay rate constants, a few aggregated bile salt molecules were not able to significantly affect the linear relationship 
between $\Delta k$ and bile salt concentration. Therefore, it was also worthwhile to be able to detect the aggregate existence below BP. RB itself allowed this detection. Indeed, the ground to first excited singlet state transition of this dye is very sensitive to the hydrogen-bonding capability of its direct microenvironment [24]. Furthermore, because of its hydrophobic nature, the RB molecule binds easily to surfactant aggregates [18,25]. RB bound to such an aggregate experiences a less hydrogen-bond donating environment, the energy difference between the first two singlet states decreases and the lowest energy band of the absorption spectrum is red-shifted. For example, the wavelength of RB absorption maximum is 548.5 $\mathrm{nm}$ in basic aqueous solution [20], $556 \mathrm{~nm}$ in sodium dodecylsulphate micelles [26], $560 \mathrm{~nm}$ in cetyltrimethylammonium bromide micelles [26] and $562 \mathrm{~nm}$ in Triton X-100 micelles [27]. In this study, PS represented the lower bile salt concentration for which a significant red-shift (1 $\mathrm{nm}$ ) of the RB absorption spectrum was observed, i.e., the lowest bile salt concentration for which some RB molecules experienced an environment different from water, presumably the first bile salt aggregates.

Keeping in mind the significance of both $\mathrm{PS}$ and $\mathrm{BP}$, it is now interesting to compare their respective values, i.e., to compare columns 2 and 3 of Tables 1, 2 and 3. PS was generally slightly larger than BP for the dihydroxy bile salts (NaCDC, NaDC, NaGDC and NaTDC) but PS was clearly smaller than BP for the trihydroxy bile salts ( $\mathrm{NaC}, \mathrm{NaGC}$ and NaTC) and their zwitterionic analogue (CHAPS). Therefore, for the dihydroxy bile salts, until BP was reached, the formation of aggregates seemed not to be detectable. Any increase in total bile salt concentration led to a corresponding increase in monomer concentration. For the trihydroxy bile salts and CHAPS, aggregates were detected at concentrations much lower than BP. Hence, before the majority of monomers participated in the formation of aggregates, some of them seemed to build, probably small, but detectable aggregates. It should be remembered at this stage that a PS lower than BP is not contradictory. As mentioned above, less than $10 \%$ of aggregated bile salt molecules would not affect significantly the linearity of the $\Delta k$ versus bile salt concentration plots. At a bile salt concentration of about $1 \mathrm{mmol} \mathrm{dm}{ }^{-3}, 10 \%$ of the total concentration represented about 0.1 
mmol dm${ }^{-3}$. In view of the small aggregation number of bile salts $(4-20)[3,4,28,29]$, this corresponded to an aggregate concentration of $10^{-3}-10^{-2} \mathrm{mmol} \mathrm{dm}^{-3}$, which was large enough to solubilize, at least partially, $4.5 \times 10^{-3} \mathrm{mmol} \mathrm{dm}^{-3} \mathrm{RB}$.

It is generally agreed that the aggregation of $\mathrm{NaDHC}$ is very limited below $100 \mathrm{mmol}$ $\mathrm{dm}^{-3}[9,14,30,31]$. BP could not be observed with this bile salt and the estimated lower limit for $\mathrm{BP}$ (5-10 $\mathrm{mmol} \mathrm{dm}^{-3}$ depending on $\mathrm{NaCl}$ concentration) did not contradict this general agreement.

Only a few studies have attempted to detect directly the concentration region over which any rise in total bile salt concentration is followed by a corresponding increase in bile salt monomer concentration. However, it is very interesting to compare these results with the PS and BP values obtained in this study. Chen et al. [32] studied the reaction between the hydrated electron and NaTC. The decay rate constant of the electron increased linearly with the NaTC concentration up to $3 \mathrm{mmol} \mathrm{dm}^{-3}$, remaining almost constant above that level. The authors interpreted $3 \mathrm{mmol} \mathrm{dm}{ }^{-3}$ as the concentration at which a pronounced aggregation of NaTC was detectable $\left(B P=3 \mathrm{mmol} \mathrm{dm}^{-3}\right)$. For CHAPS, the formation of multimers was found negligible at concentrations below $4-5 \mathrm{mmol} \mathrm{dm}^{-3}[33,34]\left(\mathrm{BP}>3 \mathrm{mmol} \mathrm{dm}^{-3}\right)$. However, our study also shows that for both NaTC and CHAPS, a few aggregates seemed to exist at lower concentrations (PS $=1 \mathrm{mmol} \mathrm{dm}^{-3}$ for NaTC and PS $=0.25 \mathrm{mmol} \mathrm{dm}^{-3}$ for CHAPS). Some previous studies support these findings. Kratohvil and co-workers $[35,36]$ used light scattering in NaTC and NaTDC aqueous solutions. They showed that the aggregation process of $\mathrm{NaTC}$ is very progressive, the first aggregates being detected at $0.4 \mathrm{mmol} \mathrm{dm}^{-3}$ in $150 \mathrm{mmol} \mathrm{dm}^{-3} \mathrm{NaCl}\left(\mathrm{PS}=0.75 \mathrm{mmol} \mathrm{dm}^{-3}\right.$ ). The aggregation process of NaTDC was found to be much sharper, beginning at $1.7 \mathrm{mmol} \mathrm{dm}^{-3}$ in $150 \mathrm{mmol} \mathrm{dm}^{-3} \mathrm{NaCl}$ ( $P S=0.75 \mathrm{mmol}$ $\mathrm{dm}^{-3}$ ) and at $1.0 \mathrm{mmol} \mathrm{dm}^{-3}$ in $600 \mathrm{mmol} \mathrm{dm}^{-3} \mathrm{NaCl}\left(P S=0.5 \mathrm{mmol} \mathrm{dm}^{-3}\right)$. Our PS values are clearly in good agreement with the lower concentration at which the onset of the aggregation process could be detected by light scattering. Very recently, Baskin and Frost [4] reported the detection of aggregates built by a few NaTDC monomers at concentrations of $0.5-1 \mathrm{mmol}$ $\mathrm{dm}^{-3}\left(\mathrm{PS}=0.75 \mathrm{mmol} \mathrm{dm}^{-3}\right.$ ). They made a similar observation for $\mathrm{NaC}$ at concentrations of 2- 
$6 \mathrm{mmol} \mathrm{dm}^{-3}$. This is larger than the PS value of $0.5 \mathrm{mmol} \mathrm{dm}^{-3}$ observed in our study. However, others [37] have observed small $\mathrm{NaC}$ aggregates at concentrations of 2-10 in water $\left(\mathrm{PS}=2 \mathrm{mmol} \mathrm{dm}^{-3}\right.$ ). For CHAPS, PS was equal to $0.25 \mathrm{mmol} \mathrm{dm}^{-3}$ and BP could unfortunately not be measured (Table 1). However, this PS value is in excellent agreement with the works of Funasaki and co-workers [33,34], who showed that the aggregation of CHAPS is a stepwise process. The first step seems to consist of dimerization and was reported by those authors to start at concentrations lower than $1 \mathrm{mmol} \mathrm{dm}^{-3}$. It is also interesting to note that the BP values found in the present study generally correspond to the lower limits of the range of published CMC values of the bile salts [for a review see 9].

In summary, for the trihydroxy bile salts ( $\mathrm{NaC}, \mathrm{NaGC}, \mathrm{NaTC}$ and $\mathrm{CHAPS}$ ), aggregates are detected at concentrations well below the concentration above which aggregates are the dominant species in the solution (PS $<\mathrm{BP})$. Therefore, the concentration range over which the aggregates are formed is not small and the IUPAC definition of the CMC does not apply to these bile salts. The appearance of the aggregates seems to be somewhat more abrupt (PS $\geq \mathrm{BP}$ ) in the case of dihydroxy bile salts ( $\mathrm{NaCDC}, \mathrm{NaDC}$, NaGDC and NaTDC). However, the aggregate polydispersity of aqueous bile salts solutions has been reported to be as high as $40 \%$ [38]. As stated in the introduction, under such conditions, the CMC values would depend on the method used to determine them. Therefore, the notion of CMC hardly seems to be applicable to aqueous solutions of both dihydroxy and trihydroxy bile salts.

BP was considered as the upper limit of the concentration range in which any rise in bile salt concentration led to a corresponding rise in bile salt monomer concentration. Conversely, BP represented the concentration limit below which any dilution of the solution would lead to disruption of aggregates. Consequently, BP could be assimilated to a micellar dissociation concentration (MDC). It has been proposed that this notion $[39,40]$ is more suitable for non-ideal surfactant systems and that it is closer to the experimental reality where dilutions and not concentrations are carried out. 
PS and BP values of dihydroxy bile salts decreased with the rise in sodium ion concentration (Tables 1, 2 and 3). For trihydroxy bile salts, PS values were also lowered but BP values remained almost constant. These observations are in good agreement with the frequently reported tendency for the aggregation process of dihydroxy bile salts to be favoured by high $\mathrm{Na}^{+}$concentrations $[11,35]$.

It is worthwhile to add some comments on the value of the reaction rate constant $\left(k_{X B}\right)$ between semi-oxidized RB and bile salt. $k_{X B}$ value was found to be very similar for all the non-conjugated bile salts studied. Glycine and, to a larger extent, taurine conjugates exhibit a higher reaction rate constant value, which seems to increase with the sodium ion concentration. Therefore, it appears that the end chain anchored at C-17 is one of the determining factors for the reaction rate constant between bile salt and semi-oxidized RB. The influence of $\mathrm{NaCl}$ concentration on the reaction rate constants $\left(k_{4}\right.$ and $\left.k_{X B}\right)$ has been previously attributed to the influence of both $\mathrm{pH}$ and ionic strength on reactions between ionic species [18].

\section{Conclusion}

This study showed that the aggregation of hydroxy bile salt NaDHC is very limited. The aggregation process of dihydroxy bile salts is relatively abrupt: the aggregates appear rapidly over a narrow concentration range. This explains why the process is often assimilated to the aggregation process of synthetic detergent and the narrow concentration range taken as the CMC. The anionic trihydroxy bile salts and their zwitterionic analogue CHAPS behave differently. Their aggregation process is very progressive and occurs over a large concentration range. This observation reinforces the idea that the number of hydroxyl groups is the major determining factor in the aggregation process of bile salts, the end chain being only a minor factor $[7,41]$. An excess of counter-ions favours the building of the first aggregates that appear at lower bile salt concentrations. 
These observations and previous reports showing a large polydispersity of BS aggregates argue seriously against the use of the notion of CMC in the characterization of bile salt solutions. We propose the use of the notion introduced by Chiu and Wang $[39,40]$, the micellar dissociation concentration (MDC), defined as the concentration below which any dilution leads to disruption of the aggregates. BP values determined here could be assimilated to MDC values.

Finally, we would like to stress the complementarity of the two spectroscopic probes used here. Semi-oxidized RB allowed the following of the rise in free bile salt concentration by the rise in total bile salt concentration, although the RB ground state was extremely sensitive to the formation of the first aggregates. 


\section{Glossary}

Aggregate: self-assembly of several molecules

Dimer: aggregate build up by two molecules

CHAPS: 3-[(3-cholamidopropyl)-dimethylammonio]-1-propanesulfonate: the zwitterionic sulfobetaine derivative of cholic acid

Critical micelle concentration $(\mathrm{CMC})$ : There is a relatively small range of concentrations separating the limit below which virtually no micelles are detected and the limit above which virtually all additional surfactant form micelles. Many properties of surfactant solutions, if plotted against the concentration, appear to change at a different rate above and below this range. By extrapolating the loci of such a property above and below this range until they intersect, a value may be obtained known as the CMC

Counter-ion: ion partially bound to a micelle and issued from the solubilization of the molecule which is building the micellar aggregates

Decay rate constant: parameter obtained when fitting decay curve with first-order kinetics.

Dihydroxy bile salt: bile salt containing two $\mathrm{OH}$ groups

Ground state: ground (fundamental) electronic state of a molecule

Monomer: single free molecule

NaC: sodium cholate

NaDC: sodium deoxycholate

NaCDC: sodium chenodoxycholate

NaDHC: sodium dehydrocholate

NaGC: sodium glycocholate

NaGDC: sodium glycodeoxycholate

NaTC: sodium taurocholate

NaTDC: sodium taurodeoxycholate

Reaction rate constant: slope obtained from linear regression of the plot of decay rate constant in function of the concentration of the reacting compound 
Post-print Author

Rose Bengal: 2',4',5',7'-tetraiodo-3,6 dichlorofluorescein

Trihydroxy bile salt: bile salt containing three $\mathrm{OH}$ groups

Triplet state: first excited triplet electronic state of a molecule 


\section{References}

[1] S. M. Meyerhoffer, L. B. McGown, Fluorescent probe studies of metal salt effects on bile salt aggregation, J. Am. Chem. Soc., 113 (1991) 2146-2149.

[2] S. Gouin, X. X. Zhu, Fluorescence and NMR studies of the effect of a bile acid dimer on the micellization of bile salts, Langmuir, 14 (1998) 4025-4029.

[3] K. Matsuoka, Y. Moroi, Micellar formation of sodium cholate and sodium ursodeoxycholate (part 1), Biochim. Biophys. Acta, 1580 (2002) 189-199.

[4] R. Baskin, L. D. Frost, Bile salt-phospholipid aggregation at submicellar concentrations, Colloids Surfaces B: Biointerfaces, 62 (2008) 238-242.

[5] K. Matsuoka, M. Suzuki, C. Honda, K. Endo, Y. Moroi, Micellization of conjugated chenodeoxy- and ursodeoxycholates and solubilization of cholesterol into their micelles: comparison with other four conjugated bile salts species, Chem. Phys. Lipids 139 (2006) 110.

[6] R. Ninomiya, K. Matsuoka, Y. Moroi, Micelle formation of sodium chenodeoxycholate and solubilization into the micelles: comparison with other unconjugated bile salts, Biochim. Biophys. Acta, 1634 (2003) 116-125.

[7] C. J. O'Connor, R. G. Wallace, Physico-chemical behavior of bile salts, Adv. Colloid Interface Sci., 22 (1985) 1-111.

[8] T. Nakashima, T. Anno, H. Kanda, Y. Sato, T. Kuroi, H. Fujii, S. Nagadome, G. Sugihara, Potentiometric study on critical micellization concentrations (CMC) of sodium salts of bile acids and their amino acid derivatives, Colloids Surfaces B: Biointerfaces, 24 (2002) 103110.

[9] S. Reis, C. Guimaraes Mountinho, C. Matos, B. de Castro, P. Gameiro, J. L. F. C. Lima, Noninvasive methods to determine the critical micelle concentration of some bile acid salts, Anal. Biochem., 334 (2004) 117-126.

[10] M. C. Carey, J. C. Montet, M. C. Phillips, M. J. Armstrong, N. A. Mazer, Thermodynamic and molecular basis for dissimilar cholesterol-solubilizing capacities by micellar solutions of 
bile salts: cases of sodium chenodeoxycholate and sodium ursodeoxycholate and their glycine and taurine conjugates, Biochemistry, 20 (1981) 3637-3648.

[11] A. Roda, A. F. Hofmann, K. J. Mysels, The influence of bile salt structure on selfassociation in aqueous solutions, J. Biol. Chem., 258 (1983) 6362-6370.

[12] R.E. Stark, P.D. Leff, S.G. Milheim, A. Kropf, Physical studies of CHAPS, a new detergent for the study of visual pigments, J. Phys. Chem., 88 (1984) 6063-6067.

[13] A. D. McNaught, D. Wilkinson, Critical micelle concentration, in: International Union of Pure and Applied Chemistry (Ed.), Compendium of Chemical Terminology - IUPAC Recommendations, Blackwell Science, Oxford, 1997, p. 93.

[14] A. Djavanbakht, K. M. Kale, R. Zana, Ultrasonic absorption and density studies of the aggregation in aqueous solutions of bile acid salts, J. Colloid Interface Sci., 59 (1977) 139148.

[15] B. Lindman, N. Kamenka, H. Fabre, J. Ulmius, T. Wielach, Aggregation, aggregate composition, and dynamics in aqueous sodium cholate solutions, J. Colloid Interface Sci., 73 (1980) 556-565.

[16] P. Mukerjee, The nature of the association equilibria and hydrophobic bonding in aqueous solutions of association colloids, Adv. Colloid Interface Sci., 1 (1967) 242-275. [17] Y. Moroi, CMC range due to polydispersity of micelles, J. Colloid Interface Sci., 141 (1991) 581-583.

[18] A. Seret, A. Van de Vorst, Photophysical investigation of rose bengal in aqueous sodium taurocholate solutions, J. Photochem. Photobiol. B: Biology, 17 (1993) 47-56.

[19] L. M. Hjelmeland, A nondenaturing zwitterionic detergent for membrane biochemistry: design and synthesis, Proc. Natl. Acad. Sci. USA, 77 (1980) 6368-6370.

[20] E. Gandin, J. Piette, Y. Lion, Purification of halogenated fluorescein derivatives by gel chromatography, J. Chromatogr., 249 (1982) 393-398.

[21] A. Seret, E. Gandin, A. Van de Vorst, Flash photolysis of Eosin in aqueous micellar dispersions, Chem. Phys. Lett., 135 (1987) 427-431. 
[22] A. Seret, A. Van de Vorst, The photochemistry of the semi-oxidized form of eosin $Y$ and rose bengal in aqueous sodium dodecylsulphate solutions, J. Photochem. Photobiol. A: Chemistry, 43 (1988) 193-206.

[23] P. C. Lee, M. A. J. Rodgers, Laser flash photokinetic studies of Rose Bengal sensitized photodynamic interactions of nucleotides and DNA, Photochem. Photobiol., 45 (1987) 79-86. [24] D. C. Neckers, Rose Bengal, J. Photochem. Photobiol. A: Chemistry, 47 (1989) 1-29. [25] A. Seret, A. Van de Vorst, Solubility properties of Eosin $Y$ and Rose Bengal triplet state in sodium dodecyl sulfate micellar solutions, J. Phys. Chem., 94 (1990) 5293-5299.

[26] M. Hoebeke, E. Gandin, J. Decuyper, A. Van de Vorst, Effects of micellar adsorption on the photosensitizing properties of xanthene dyes, J. Photochem., 35 (1986) 245-250.

[27] S. Kundu, S. Panigrahi, A. Pal, S. Kumar Ghosh, S. Nath, S. Praharaj, S. Basu, T. Pal, Dye-micelle aggregate formation for effective photobleaching, Dye and Pigments, 69 (2006) 177-184.

[28] A. Jover, F. Meijide, E. Rodriguez Nunez, J. Vazquez Tato, M. Mosquera, Aggregation number for sodium deoxycholate from steady-state and time-resolved fluorescence, Langmuir, 13 (1997) 161-164.

[29] M. Janich, J. Lange, H. Graener, R. Neubert, Extended light scattering investigations on dihydroxy bile salt micelles in low-salt aqueous solutions, J. Phys. Chem. B, 102 (1998) 5957-5962.

[30] C. J. O'Connor, B. T. Ch'ng, R. G. Wallace, Studies in bile salt solutions: 1. Surface tension evidence for a stepwise aggregation model, J. Colloid Interface Sci., 95 (1983) 410419.

[31] P. K. Jana, S. P. Moulik, Interaction of bile salts with hexadecyitrimethyiammonium bromide and sodium dodecyl dulfate, J. Phys. Chem., 95 (1991) 9525-9532.

[32] M. Chen, M. Grätzel, J. K. Thomas, Kinetic Studies in Bile Acid Micelles, J. Am. Chem. Soc., 97 (1975) 2052-2057.

[33] N. Funasaki, S. Hada, S. Neya, Micelle Formation of a Sulfobetaine Derivative of Cholic Acid, Chem. Lett., (1990) 1075-1078. 
[34] N. Funasaki, S. Hada, S. Neya, Odd-even alternation in the aggregation number dependence of stepwise aggregation constants, J. Phys. Chem., 95 (1991) 1846-1850.

[35] J. P. Kratohvil, W. P. Hsu, M. A. Jacobs, T. M. Aminabhavi, Y. Mukunoki, Concentrationdependent aggregation patterns of conjugated bile salts in aqueous sodium chloride solutions, Colloid Polym. Sci., 261 (1983) 781-785.

[36] H. Matsuoka, J. P. Kratohvil, N. Ise, Small-angle x-ray scattering from solutions of bile salts: sodium taurodeoxycholate in aqueous electrolyte solutions, J. Colloid Interface Sci., 118 (1987) 387-396.

[37] Mónika Megyesi and László Biczók, Berberine Alkaloid as a Sensitive Fluorescent Probe for Bile Salt Aggregates, J. Phys. Chem. B, 111 (2007) 5635-5639.

[38] N. A. Mazer, M. C. Carey, R. F. Kwasnick, G. B. Benedek, Quasielastic light scattering studies of aqueous biliary lipid systems. Size, shape, and thermodynamics of bile salt micelles, Biochemistry, 18 (1979) 3064-3075.

[39] Y. C. Chiu, S. J. Wang, The micellar dissociation concentration of impure sodium dodecyl sulfate systems in water, Colloids Surfaces, 48 (1990) 297-309.

[40] Y. C. Chiu, S. J. Wang, The micellar dissociation concentration of some commercial surfactants containing carboxymethyl ethoxylates, Colloids Surfaces, 48 (1990) 311-312. [41] M. C. Carey, D. M. Small, Micelle formation by bile salts. Physical-chemical and thermodynamic considerations, Arch. Intern. Med., 130 (1972) 506-527. 


\section{Figure captions}

Fig. 1. Difference $\left(\Delta k=k-k_{0}\right)$ between the decay rate constant $(k)$ and the decay rate constant without bile salt $\left(k_{0}\right)$ of RB semi-oxidized radical versus bile salt concentration in aqeuous solution containing $10 \mathrm{mmol} \mathrm{dm}^{-3} \mathrm{NaOH}$. The oblique line was obtained by linear regression performed in the region where $k$ increased. The horizontal line represents the mean $\Delta k$ value in the region where $k$ was found to be constant. (A) NaDHC, (B) NaDC, (C) $\mathrm{NaC},(D) \mathrm{NaGC}$. 
Post-print Author

\section{Tables}

Table 1. Aqueous solutions containing $10 \mathrm{mmol} \mathrm{dm}^{-3} \mathrm{NaOH}$.

\begin{tabular}{|c|c|c|c|c|c|}
\hline \multirow[t]{2}{*}{ Bile salt } & \multirow{2}{*}{$\begin{array}{c}\text { PS } \\
\left(\mathrm{mmol} \mathrm{dm}^{-3}\right)\end{array}$} & \multirow{2}{*}{$\begin{array}{c}\mathrm{BP} \\
\left(\mathrm{mmol} \mathrm{dm}^{-3}\right)\end{array}$} & \multicolumn{2}{|c|}{$\mathrm{k}_{\mathrm{X} 4}\left(10^{8} \mathrm{dm}^{-3} \mathrm{~mol}^{-1} \mathrm{~s}^{-1}\right)$} & \multirow{2}{*}{$\begin{array}{c}\mathrm{k}_{\mathrm{XB}} \\
\left(10^{5} \mathrm{dm}^{-3}\right. \\
\left.\mathrm{mol}^{-1} \mathrm{~s}^{-1}\right)\end{array}$} \\
\hline & & & {$[\mathrm{BS}]<\mathrm{BP}$} & {$[\mathrm{BS}]>\mathrm{BP}$} & \\
\hline none & -- & -- & \multicolumn{2}{|c|}{$8.38 \pm 1.68$} & -- \\
\hline $\mathrm{NaDHC}$ & 5.0 & $>10$ & \multicolumn{2}{|c|}{$7.14 \pm 1.43$} & $1.79 \pm 0.36$ \\
\hline $\mathrm{NaCDC}$ & 2.0 & 1.0 & $8.74 \pm 1.75$ & $8.10 \pm 1.62$ & $1.22 \pm 0.24$ \\
\hline $\mathrm{NaDC}$ & 2.0 & 1.3 & $8.10 \pm 1.62$ & $8.05 \pm 1.61$ & $1.32 \pm 0.26$ \\
\hline $\mathrm{NaGDC}$ & 1.0 & 0.88 & $7.08 \pm 1.40$ & $7.83 \pm 1.57$ & $0.95 \pm 0.19$ \\
\hline NaTDC & 1.0 & 1.75 & $7.88 \pm 1.58$ & $8.42 \pm 1.68$ & $3.26 \pm 0.65$ \\
\hline $\mathrm{NaC}$ & 2.0 & 3.3 & $7.34 \pm 1.45$ & $8.05 \pm 1.61$ & $0.96 \pm 0.19$ \\
\hline $\mathrm{NaGC}$ & 1.5 & 3.5 & $9.18 \pm 1.84$ & $6.51 \pm 1.32$ & $2.88 \pm 0.58$ \\
\hline NaTC & 1.0 & $3.0^{b}$ & $7.44 \pm 1.49$ & n.m. ${ }^{a}$ & $37 \pm 8$ \\
\hline${ }_{c}^{C H A P S}$ & 0.25 & $>3.0$ & n.m. ${ }^{a}$ & n.m. ${ }^{a}$ & $0.67 \pm 0.13$ \\
\hline
\end{tabular}

${ }^{a}$ n.m.: not measurable

${ }^{b}$ [15]

${ }^{c}$ without $\mathrm{NaOH}$ 
Table 2. Aqueous solutions containing $10 \mathrm{mmol} \mathrm{dm}^{-3} \mathrm{NaOH}$ and $140 \mathrm{mmol} \mathrm{dm}^{-3} \mathrm{NaCl}$.

\begin{tabular}{|c|c|c|c|c|c|}
\hline \multirow[t]{2}{*}{ Bile salt } & \multirow{2}{*}{$\begin{array}{c}\text { PS } \\
\left(\mathrm{mmol} \mathrm{dm}^{-3}\right)\end{array}$} & \multirow{2}{*}{$\begin{array}{c}\mathrm{BP} \\
\left.(\mathrm{mmol} \mathrm{dm})^{-3}\right)\end{array}$} & \multicolumn{2}{|c|}{$\mathrm{k}_{\mathrm{X} 4}\left(10^{9} \mathrm{dm}^{-3} \mathrm{~mol}^{-1} \mathrm{~s}^{-1}\right)$} & \multirow{2}{*}{$\begin{array}{c}\mathrm{k}_{\mathrm{XB}} \\
\left(10^{5} \mathrm{dm}^{-3}\right. \\
\left.\mathrm{mol}^{-1} \mathrm{~s}^{-1}\right)\end{array}$} \\
\hline & & & {$[\mathrm{BS}]<\mathrm{BP}$} & {$[\mathrm{BS}]>\mathrm{BP}$} & \\
\hline none & -- & -- & \multicolumn{2}{|c|}{$1.40 \pm 0.28$} & -- \\
\hline $\mathrm{NaDHC}$ & 4.0 & $>6$ & \multicolumn{2}{|c|}{$1.31 \pm 0.26$} & $2.41 \pm 0.48$ \\
\hline $\mathrm{NaCDC}$ & 1.0 & n.m. ${ }^{a}$ & \multicolumn{2}{|c|}{$1.52 \pm 0.30$} & n.m. ${ }^{a}$ \\
\hline $\mathrm{NaDC}$ & 1.25 & 1.0 & $1.63 \pm 0.33$ & $1.62 \pm 0.32$ & $1.39 \pm 0.28$ \\
\hline $\mathrm{NaGDC}$ & 0.50 & 0.25 & $1.19 \pm 0.24$ & $1.70 \pm 0.34$ & $1.84 \pm 0.37$ \\
\hline NaTDC & 0.75 & 1.0 & $1.62 \pm 0.32$ & $1.69 \pm 0.34$ & $4.10 \pm 0.82$ \\
\hline $\mathrm{NaC}$ & 0.50 & 2.75 & $1.75 \pm 0.35$ & $1.50 \pm 0.30$ & $1.00 \pm 0.20$ \\
\hline $\mathrm{NaGC}$ & 1.0 & 3.0 & $1.40 \pm 0.28$ & $1.50 \pm 0.30$ & $1.28 \pm 0.46$ \\
\hline NaTC & 0.75 & 2.5 & n.m. ${ }^{a}$ & n.m. ${ }^{a}$ & n.m. ${ }^{a}$ \\
\hline
\end{tabular}

${ }^{a}$ n.m.: not measurable

${ }^{\mathrm{b}}$ [15] 
Table 3. Aqueous solutions containing $10 \mathrm{mmol} \mathrm{dm}^{-3} \mathrm{NaOH}$ and $590 \mathrm{mmol} \mathrm{dm}^{-3} \mathrm{NaCl}$.

\begin{tabular}{|c|c|c|c|c|c|}
\hline \multirow[t]{2}{*}{ Bile salt } & \multirow{2}{*}{$\begin{array}{c}\text { PS } \\
\left(\mathrm{mmol} \mathrm{dm}^{-3}\right)\end{array}$} & \multirow{2}{*}{$\begin{array}{c}\mathrm{BP} \\
\left(\mathrm{mmol} \mathrm{dm}^{-3}\right)\end{array}$} & \multicolumn{2}{|c|}{$\mathrm{k}_{\mathrm{X} 4}\left(10^{9} \mathrm{dm}^{-3} \mathrm{~mol}^{-1} \mathrm{~s}^{-1}\right)$} & \multirow{2}{*}{$\begin{array}{c}\mathrm{k}_{\mathrm{XB}} \\
\left(10^{5} \mathrm{dm}^{-3}\right. \\
\left.\mathrm{mol}^{-1} \mathrm{~s}^{-1}\right)\end{array}$} \\
\hline & & & {$[\mathrm{BS}]<\mathrm{BP}$} & {$[\mathrm{BS}]>\mathrm{BP}$} & \\
\hline none & -- & -- & \multicolumn{2}{|c|}{$2.10 \pm 0.42$} & -- \\
\hline $\mathrm{NaDHC}$ & 1.5 & $>5$ & \multicolumn{2}{|c|}{$2.05 \pm 0.41$} & $4.04 \pm 0.81$ \\
\hline $\mathrm{NaCDC}$ & 0.25 & n.m. ${ }^{a}$ & \multicolumn{2}{|c|}{$1.67 \pm 0.33$} & n.m. ${ }^{a}$ \\
\hline $\mathrm{NaDC}$ & 0.75 & 0.63 & $1.77 \pm 0.36$ & $1.74 \pm 0.35$ & $1.49 \pm 0.30$ \\
\hline $\mathrm{NaGDC}$ & 0.50 & n.m. ${ }^{a}$ & \multicolumn{2}{|c|}{$1.86 \pm 0.37$} & n.m. ${ }^{a}$ \\
\hline NaTDC & 0.50 & 0.38 & $1.57 \pm 0.34$ & $1.86 \pm 0.37$ & $4.92 \pm 0.98$ \\
\hline $\mathrm{NaC}$ & 0.50 & 3.3 & $2.07 \pm 0.41$ & $2.35 \pm 0.47$ & $1.02 \pm 0.20$ \\
\hline $\mathrm{NaGC}$ & 0.50 & 2.8 & $2.21 \pm 0.44$ & n.m. ${ }^{a}$ & $3.37 \pm 0.67$ \\
\hline $\mathrm{NaTC}$ & 0.50 & 2.5 & n.m. ${ }^{a}$ & n.m. ${ }^{a}$ & n.m. ${ }^{a}$ \\
\hline
\end{tabular}

${ }^{a}$ n.m.: not measurable

${ }^{\mathrm{b}}$ [15] 


\section{FIGURE 1}
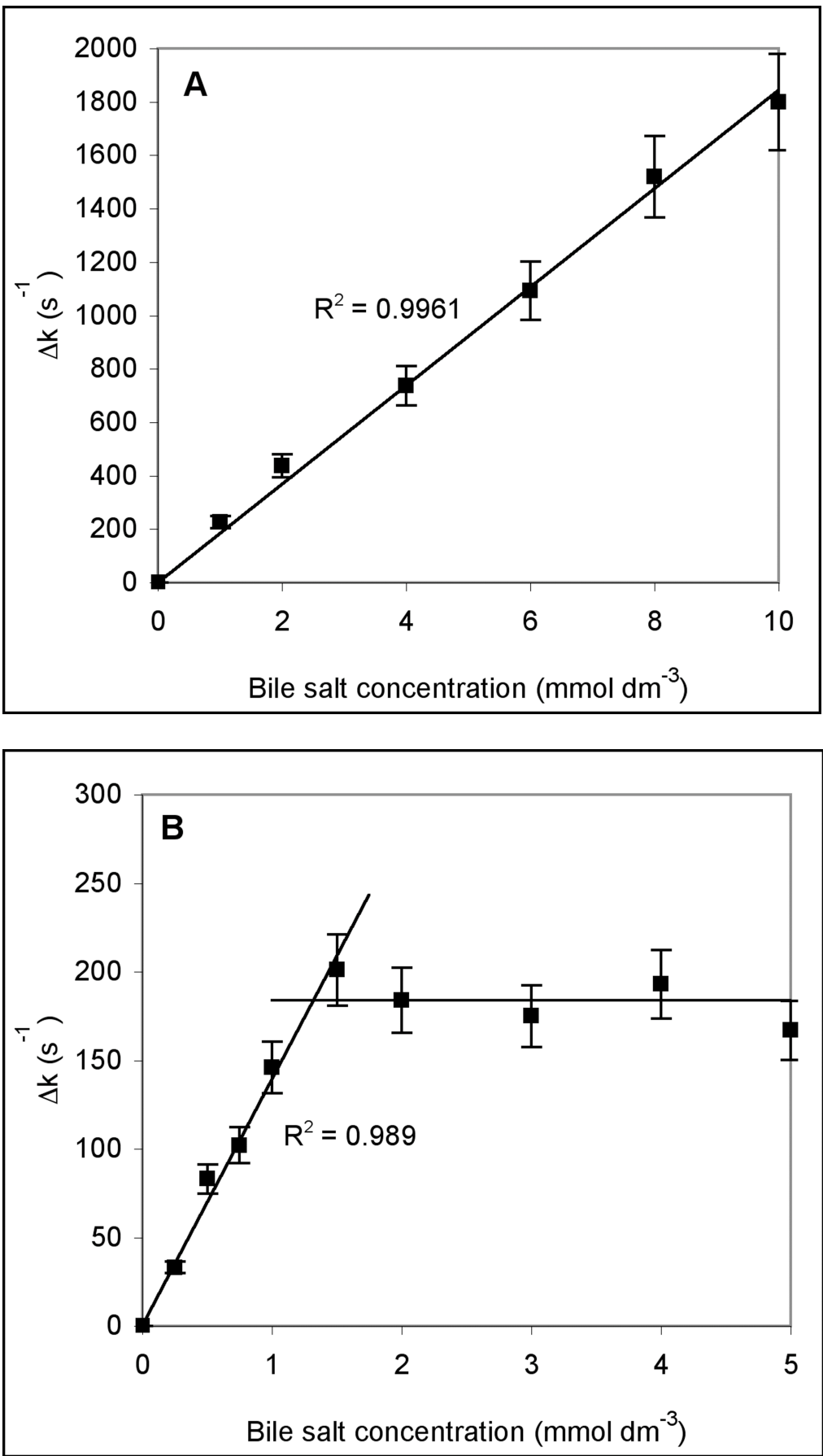

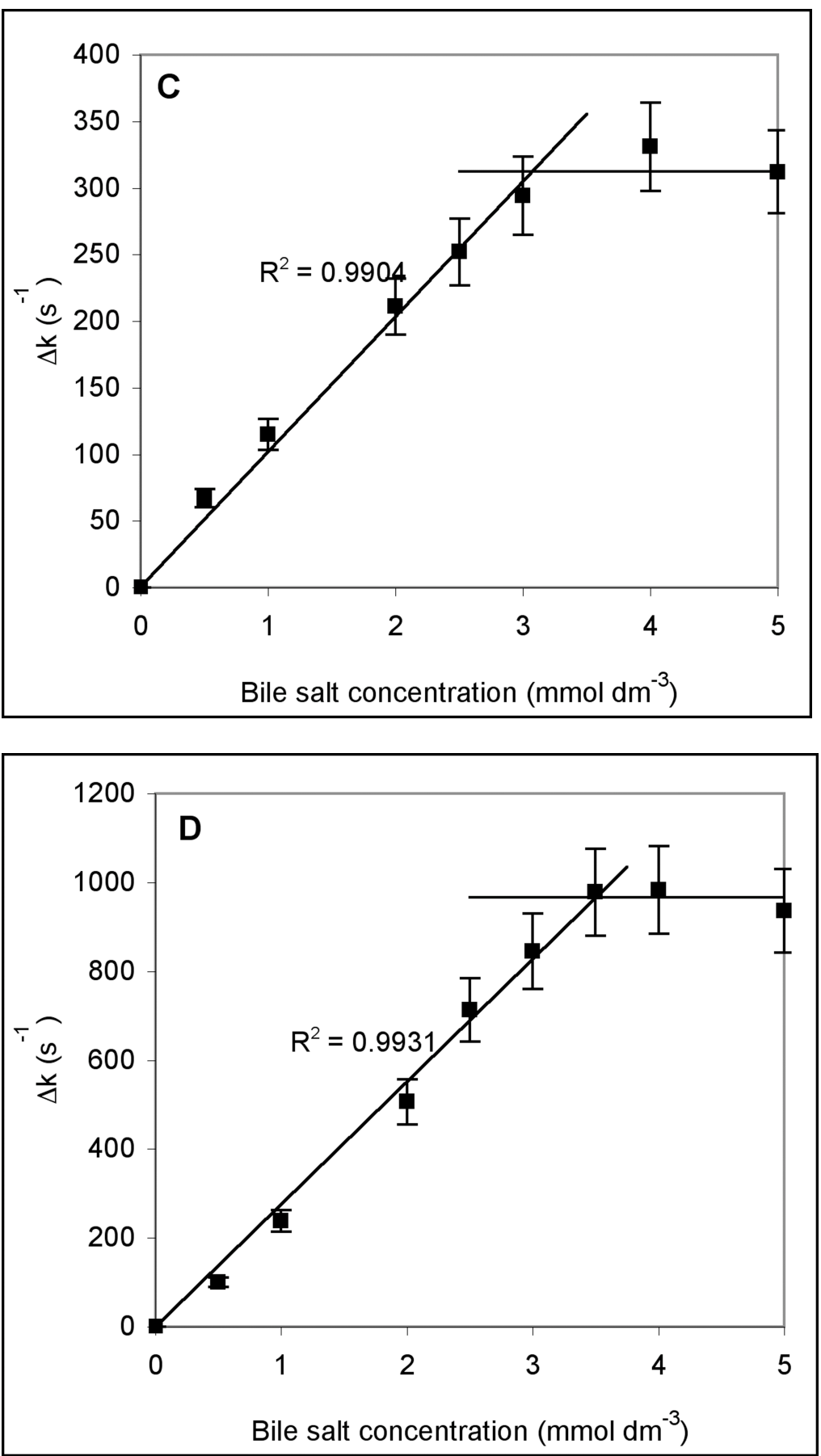